\title{
Simultaneous Occurrence of Systemic Lupus Erythematosus, Rheumatoid Arthritis, Hashimoto's Thyroiditis and Membranous Glomerulonephritis
}

Lilia Baili, Imène Rachdi, Fatma Daoud, Zohra Aydi, Basma Ben Dhaou, Samir Kochbati, Fatma Boussema

Internal Medicine Department, Habib Thameur Hospital, Tunis, Tunisia

\begin{abstract}
Introduction: Membranous glomerulonephritis is commonly described in systemic lupus erythematosus (SLE) and hypothyroidism.
\end{abstract}

Clinical presentation: We report a case of a 40-year-old woman who presented with a membranous glomerulonephritis associated with SLE, rheumatoid arthritis and hypothyroidism due to Hashimoto's thyroiditis.

Conclusions: The simultaneous occurrence of these three diseases as possible causes of membranous glomerulonephritis is extremely exceptional.

Keywords: Systemic lupus erythematosus, rheumatoid arthritis, Hashimoto's thyroiditis, membranous glomerulonephritis, overlap syndrome

Received: $30 / 07 / 2014$

Accepted: $24 / 10 / 2014$

Published: $11 / 11 / 2014$

How to cite this article: Baili L, Rachdi I, Daoud F, Aydi Z, Ben Dhaou B, Kochbati S, Boussema F. Simultaneous Occurrence of Systemic Lupus Erythematosus, Rheumatoid Arthritis, Hashimoto's Thyroiditis and Membranous Glomerulonephritis. EJCRIM 2014;1:doi: 10.12890/2014_000122 Conflicts of Interests: The authors declare that they have no conflicts of interest related to this research.

\section{Introduction}

Membranous glomerulonephritis, described as Class V of lupus nephritis, is rarely observed in rheumatoid arthritis (RA) and Hashimoto's thyroiditis [1-3].

We report an interesting case of concomitant systemic lupus erythematosus (SLE), RA, Hashimoto's thyroiditis and a membranous glomerulonephritis.

\section{Case report}

A 40-year-old woman with no medical past history was referred for limb oedema and inflammatory arthralgia for the previous 6 months. Physical examination revealed diffuse oedema, synovitis of proximal interphalangeal and 
metcarpo-phalangeal joints and thyroid goitre. Her blood pressure was 120/80 mmHg. Biological examination showed normocytic anaemia (haemoglobinaemia=9.1 g/l), lymphopenia (lymphocyte count 1300/mm ${ }^{3}$ ), hypoprotidaemia (28 $\mathrm{g} / \mathrm{l})$, hypoalbuminaemia $(9.4 \mathrm{~g} / \mathrm{dl}$ ) with serum creatinine at $89 \mu \mathrm{mol} / \mathrm{l}$ (creatinine clearance $60 \mathrm{ml} / \mathrm{min}$ ), hypercholesterolaemia $(13.3 \mathrm{mmol} / \mathrm{l})$ and hypertriglyceridaemia $(9.6 \mathrm{mmol} / \mathrm{l})$. Urinary examination revealed massive proteinuria $(8.85 \mathrm{~g} / 24 \mathrm{~h})$, leucocyturia $\left(400 / \mathrm{mm}^{3}\right)$ and haematuria $\left(69 / \mathrm{mm}^{3}\right)$. TSH level was elevated at $16.3 \mathrm{mUI} / \mathrm{l}(0.2-$ 5 ) and FT4 was low at $5 \mathrm{pmol} / \mathrm{I}(6-23)$. Serological tests of viral hepatitis B and C, HIV, EBV and CMV were negative. Complement was consumed (C3, $0.73 \mathrm{~g} / \mathrm{l} ; \mathrm{C} 4,0.14 \mathrm{~g} / \mathrm{l})$. Antinuclear antibodies (ANA) and DNA antibodies were positive (ANA=1/320 controlled 1/1200 homogeneous speckled; DNA antibodies: IFA Crithidia lucilae +++, ELISA +++; ENT: anti $\mathrm{Sm}+$, antinucleosome + ). Rheumatoid factors ( $\mathrm{RF}, 187 \mathrm{UA} / \mathrm{ml}(\mathrm{N}<30)$ and anticyclic citrullinated peptide antibodies were positive (anti CCP, $98 \mathrm{U} / \mathrm{ml}(\mathrm{N}<25))$. Anti-thyroglobulin antibodies were positive at high titre $(980 \mathrm{Ul} / \mathrm{ml}$; normal $\leq 100)$. Cervical ultrasound revealed a multinodular goitre. A diagnosis of Hashimoto's thyroiditis was then made. X-rays of the wrists showed severe carpitis. The diagnosis of SLE was retained considering four ACR criteria: lymphopenia, positive ANA, positive anti-DNA and proteinuria. A diagnosis of RA was made based on distal joint synovitis, radiological carpitis and positive immunological tests. A percutaneous renal biopsy was performed and the histopathological examination showed a membranous glomerulonephritis with focal mesangial proliferation and segmental hyalinosis (Figs. 1 and 2). Immunoglobulin type $\mathrm{G}$ and $\mathrm{M}$, complement $(\mathrm{C} 3, \mathrm{C} 1 \mathrm{q})$ and fibrinogen deposits were detected on standard direct immunofluorescence.

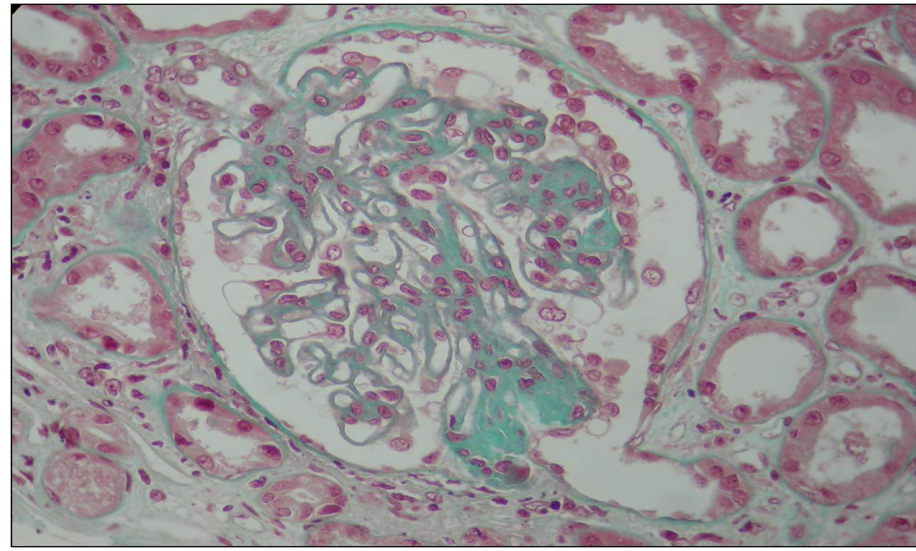

Figure 1: Photo of the histopathological examination of kidney biopsy (Trichrome Masson, magnification 400x): membranous

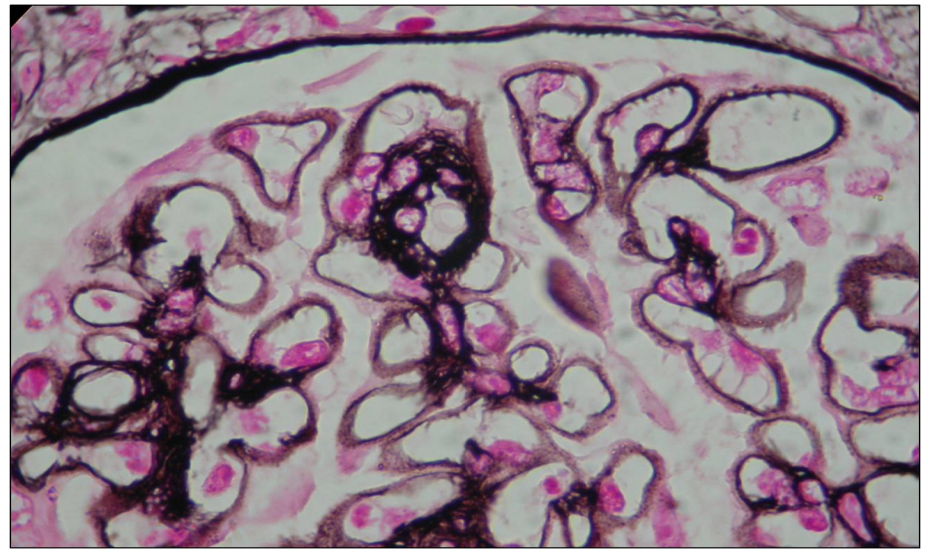

Figure 2: Photo of histopathological examination of kidney biopsy (silver staining): membranous glomerulonephritis and spikes. glomerulonephritis with focal mesangial proliferation.

The patient was treated with intravenous boli of methylprednisolone relayed with oral corticosteroids at a dose of 1 $\mathrm{mg} / \mathrm{kg} /$ day. Immunosuppressive treatment with six bimensual boli of cyclophosphamide relayed with azathioprine was also performed. She was also treated with thyroid hormones. The outcome was favourable, marked by an improvement of the oedema and a normalization of thyroid hormone levels. Urine analysis showed regression of proteinuria $(0.23$ $\mathrm{g} / 24 \mathrm{~h})$. 


\section{Discussion}

Membranous glomerulonephritis is a pattern of injury that results from subendothelial and mesangial deposition of immunoglobulins caused by persistent antigenaemia and/or circulating immune complexes [4]. It is typically classified as idiopathic or secondary to infections, drugs, toxins, malignancy or autoimmune disease especially to SLE.

In this case, we analyze the occurrence of membranous glomerulonephritis in a patient with three autoimmune diseases. Autoimmune disorders can be organ-specific or they can involve multiple organs. The common characteristic of all these disorders is the production of different autoantibodies against various autoantigens along with inflammation.

Membranous glomerulonephritis represents about $20 \%$ of clinically significant renal disease in SLE [1]. Few studies have directly addressed the pathogenesis of membranous glomerulonephritis. Natural history studies of membranous glomerulonephritis in SLE suggest a relatively low rate of progression to end-stage renal disease but a high rate of significant comorbidities [5]. Considering the nephrotic syndrome, the patient was treated with immunosuppressive therapies, including corticosteroids and cyclophosphamide.

Renal involvement during RA is rare [6]. Renal lesions directly due to the disease itself are infrequent. Regarding membranous glomerulonephritis, the relationship between with RA remains unclear. Membranous glomerulonephritis is generally accepted as the most frequent histological lesion during treatment with gold salts, D-penicillamine and bucillamine, although other authors have described a direct relationship with RA [2, 7]. Membranous glomerulonephritis had occurred in our patient before beginning treatment. So, it may be directly related to RA. In fact, even if the pathogenesis of membranous glomerulonephritis in RA is still unknown, it is hypothesized that the presence of circulating immune complexes and rheumatoid factor, or alteration in T cell immune response and the presence of proinflammatory cytokines, may have played a role in the pathogenesis of the nephropathy.

Thyroid pathology has a high prevalence in the general population, although autoimmune aetiology is rare. It is associated with a variety of glomerulonephritis types in very few cases, the most frequent being membranous glomerulonephritis [8]. As reported by some authors, simultaneous occurrence of thyroid and glomerular disease could be explained by the existence of an autoimmune pathogenesis common to both conditions, and incidence could be higher than suspected, with proteinuria being found in a high proportion of patients with autoimmune thyroiditis and Graves' disease [8-10]. In our case, thyroiditis was diagnosed based on positive antithyroid antibodies, and its clinical manifestation was a clinical hypothyroidism. The parallelism seen between remission of nephrotic syndrome and TSH normalization under treatment with thyroid hormone and corticosteroids should be noted. So, in cases of apparently idiopathic nephrotic syndrome, thyroid function needs to be investigated $[9,10]$. Membranous glomerulonephritis in this case is probably secondary to autoimmune disorders caused by the exceptional simultaneous occurrence of these three autoimmune diseases.

\section{Learning Points}

- Lupus is a classical aetiology of membranous glomerulonephritis.

- Membranous glomerulonephritis is an uncommon extra-articular manifestation of rheumatoid arthritis.

- Autoimmune thyroiditis with nephrotic syndrome is marked by predominant membranous glomerulonephritis. 
- It is necessary to perform an analysis of the thyroid hormones in every patient with nephrotic syndrome as part of an aetiological screening process.

- The simultaneous occurrence of these three diseases as possible causes of membranous glomerulonephritis is extremely rare.

\section{References}

1. Mok CC. Membranous nephropathy in systemic lupus erythematosus: a therapeutic enigma, Nat Rev Nephrol 2009;5:212-220.

2. Maruotti N, Corrado A, Gaudio A, Cantatore FP. Membranous nephropathy in rheumatoid arthritis: a case report, Clin Exp Rheumatol 2009;27:840-842.

3. Weetman AP, Tomlinson K, Amos N, Lazarus JH, Hall R, McGregor AM. Proteinuria in autoimmune thyroid disease, Acta Endocrinol 1985;109:341-347.

4. Sethi S, Fervenza FC. Membranoproliferative glomerulonephritis: pathogenetic heterogeneity and proposal for a new classification, Semin Nephrol 2011;31:341-348.

5. Austin HA, Illei GG. Membranous lupus nephritis, Lupus 2005;14:65-71.

6. Stokes MB, Foster K, Markowitz GS, Ebrahimi F, Hines W, Kaufman D et al. Development of glomerulonephritis during anti-TNF- $\alpha$ therapy for rheumatoid arthritis, Nephrol Dial Transplant 2005;20:1400-1406.

7. Baba N, Nomura T, Sakemi T, Uchida M, Watanabe T. Membranous glomerulonephritis probably related to bucillamine therapy in two patients with rheumatoid arthritis, Nippon Jinzo Gakkai Shi 1991;33:629-634.

8. Esteve V, Fontseré, Taurina A, Ramirez M. Enfermedad de Graves, hipotiroidismo farmacológico y síndrome nefrótico por enfermedad de cambios mínimos, Nefrología 2008;28:230-231.

9. Valentín M, Bueno B, Gutiérrez E, Martínez A, González E, Espejo B et al. Glomerulonefritis membranoproliferativa hipocomplementémica asociada a tiroiditis autoinmune, Nefrología 2004;24:43-48.

10.Nishiki, Murakami Y, Yamane Y, Kato Y. Steroid-sensitive nephrotic syndrome, sarcoidosis and thyroiditis: a new syndrome? Nephrol Dial Transplant 1999;14:2008-2010. 